\title{
The Effects of Pre-Service Teachers' Chemistry Perceptions on their Academic Achievement
}

\author{
Samuel Arthur Ayoberd ${ }^{1}$, Boniface Yaayin ${ }^{2}$ Collins Dauda Amadu ${ }^{3}$ \\ 1. Department of Science Education, Tamale College of Education, P. O. Box 1 E/R, Tamale, Ghana, \\ Tel: +233-240967775, Email:* samuelayoberd@gmail.com \\ 2. Department of Science Education, Tamale College of Education, P. O. Box 1 E/R, Tamale, Ghana, \\ Tel: +233-245176857, Email: niberbon@yahoo.co.uk \\ 3.Department of Science Education, Tamale College of Education, P. O. Box 1 E/R, Tamale, Ghana, \\ Tel: +233-244111899, Email: acollinsdauda@yahoo.com
}

\begin{abstract}
The purpose of this study was to investigate the effects of pre-service teachers' chemistry perceptions on their academic achievement. The study was hinged on the behaviourist and constructivist methodologies of perception studies. The study employed a quantitative research method by using students' end of first semester chemistry examination results as the measure of chemistry achievement and a survey questionnaire (Chemistry Perception Questionnaire (CPQ), which was a Likert-type questionnaire. Data from end of first semester examination and CPQ were collected from 72 Level 200 and 60 Level 300 elective science pre-service teachers' of Tamale College of Education. Pearson's moment correlation was run separately for the perceptions and academic achievements of the pre-service teachers. The findings of the study reveal that there is a negative correlation between the perceptions held by pre-service science teachers of Tamale College of Education about the chemistry curriculum and their academic achievement $(r=-0.046$ and $r=-0.078$ for Levels 200 and 300 students respectively). This means that as their perceptions deepened, their academic achievement decreased. The study also revealed that the polarity of perception statements does not significantly affect the correlation coefficient. It is however, very imperative to combine both negative and positive statements in order to reduce acquiescence bias. In conclusion, chemistry educators must seek to resolve students' perceptual difficulties as it is very crucial in setting the tone for their academic progression in excellence.
\end{abstract}

Keywords: Pre-service Teachers, Chemistry perception, Polarity of perception questions, Achievement DOI: $10.7176 / \mathrm{JEP} / 11-21-20$

Publication date:July 31 st 2020

\section{Introduction}

The goal of science teaching is to produce scientifically literate persons, good problem solvers, having the ability to think creatively and having both the confidence and competence to participate fully in local and global matters (National Council for Curriculum and Assessment (NaCCA), 2019). To achieve science teaching goals, the goals must be translated into meaningful behavioural learning outcomes. From Benjamin Bloom's taxonomies of educational objectives and other educational researchers point of view, learning outcomes are looked at in three important domains; affective, cognitive and psychomotor (Mensah \& Appiah, 2015).

It is important to note that many educational systems over the world reward outputs of the cognitive domains to the disadvantage of the affective and psychomotor domains. From the instructional design stage to the implementation of the instructional strategies, emphasis has been laid on students' ability to recall facts and figures. Assessment of students' learning and placement programs are geared towards rewarding students with the greater ability (brain power) to rehearse and recall contents and sometimes little application of content to everyday situations. For instance, in Ghana and most Anglophone West African countries, the student' cognitive ability in scoring higher marks forms the basis for their enrollment into certain prestigious science oriented courses like Medicine, Pharmacy and Engineering, without recourse to the students' interest, motivation, competencies and passion for the programme of study. In some cases, parents and guardians coerce their wards to train for certain professions their wards have no passion for.

It is however worth noting that throughout the years, scientists, science educators as well as curriculum developers and teachers have emphasized the importance of the affective domain in general and attitudes in particular, as central components of the goals for teaching and learning the sciences (Hofstein \& Mamlok-Naaman, 2011). Indeed the most important reason for science education is to awaken in the child, the excitement, the sense of joy, 
the desire to become a professional scientist, and the love to exhibit intellectual power of science (Das, Amrita \& Singh 2014). In other words, effective science teaching must be geared towards helping the learner develop a positive perception towards the subject and not necessarily making the learner acquire the skills of rehearsing and recalling facts and figures. Scientific facts keep on changing with time but with the right attitudes and competencies; new discoveries, adaptations and applications of knowledge to new situations are made possible. Affective attributes such as perceptions and attitudes, are very critical elements that need to be developed in learners due to their significant influence on the learner.

The term perception has been examined variously by different authors and researchers depending on which theoretical and philosophical persuasion they believe in or belong to. For instance, Norman (2002, pp.73-74 ) defines perception in a much broader sense to "encompass both conscious and unconscious effects of sensory stimulation on behaviour". Norman defined perception this way due to his reconciliatory approach to handling the constructivist and ecological theories of perception. Wells (2003) looked at perception to include an attitude, view, belief or opinion one holds about an object or event. This definition also contains elements that encompass both the direct and indirect approaches to perception and this is in tandem with the view point of this paper.

Ample evidences abound (Anamuah-Mensah, 1995; Yüksel \& Geban, 2014) pointing to the fact that a direct relationship exists between students' academic performance or achievements in chemistry and their perception in chemistry. This is evidenced in the study conducted by Kubiatko, Mrascova and Janko (2012), where it was established that there is a strong correlation between learners' perceptions and their academic achievements. Kaya and Certin (2012) corroborated the findings of Kubiatco et al (2012) with the assertion that there is a widespread consensus for a strong correlation between chemistry students' anxiety levels and their achievement in science and laboratory courses even though their own study showed the contrary.

In the most general sense, academic achievement means the level of attaining aims predicted in a certain educational process. Academic achievement is generally determined through examinations conducted for measuring knowledge and skills obtained in courses given in educational institutions (Sünbül \& Gürsel, 2001) cited in (Yüksel \& Geban, 2014).

Kurbanoglo and Akin (2015) in their study to develop a scale to measure organic chemistry anxiety levels of university students in Turkey came out with some noteworthy revelations. A Pearson moment correlation was used to examine the relationships between organic chemistry anxiety and the organic chemistry achievement. Correlational results $(\mathrm{r}=-0.47)$ proved that there are significant correlations between organic chemistry achievement and organic chemistry anxiety. In other words, as students' organic chemistry anxiety levels increased, their organic chemistry achievement decreased.

Identification of perceptions held by students and society in general about any science subject and seeking solutions to address the negative perceptions is very essential part of educational research (Cavallo \& Laubach, 2001). A classic example of the consequence of poor handling of students' perceptions about chemistry is reported in the findings of Mahajan and Singh (2005) where their research revealed that underperformance in chemistry at the undergraduate level were due to the fact that the students found chemistry concepts very complicated and that the students did not want to put in effort themselves, rather believed in spoon-feeding by their instructors.

Many scientific studies about science students' perceptions have been conducted across the globe with few being done in Ghana to ascertain the veracity of students' perceptions in chemistry and the resultant implication on their academic achievement. The purpose of this paper therefore, is to examine the relationship between students' perceptions about the Colleges of Education (CoE) Chemistry curriculum and their academic achievements.

\section{Research questions}

This paper sought to find answers to the following questions:

1. What is the relationship between pre-service teachers' perceptions and their academic achievements in chemistry?

2. Does the polarity of perception statements influence the correlation between pre-service teachers' perception and their academic achievement? 


\section{Methodology}

The study was hinged on the behaviourist and constructivist methodologies of perception studies. The research employed a quantitative research method by using students' end of first semester chemistry examination results (conducted by Institute of Education - University of Cape Coast) as the measure of chemistry achievement and a survey questionnaire (Chemistry Perception Questionnaire (CPQ), which was a Likert-type questionnaire. Data from end of first semester examination and CPQ were collected from Level 200 and Level 300 elective science pre-service teachers' of Tamale College of Education.

The CPQ were administered in person by the researchers to the 72 and 60 Levels 200 and 300 elective science preservice teachers with a return rate of $95.89 \%$ and $83.33 \%$ respectively. Likert scale- type questionnaires consisting of seven positive statements and fourteen negative statements were used in gathering data for the perception study. The positive statements were scored as $\mathrm{SA}=5, \mathrm{~A}=4, \mathrm{U}=3, \mathrm{D}=2, \mathrm{SD}=1$ and the negative statements were scored as $\mathrm{SA}=1, \mathrm{~A}=2, \mathrm{U}=3, \mathrm{D}=4$ and $\mathrm{SD}=5$.

The percentage score of the additive value of all sub-scales for a student represented his/her chemistry perception score. Students' end of first semester elective chemistry examination (organized by Institute of Education University of Cape Coast) results constituted their academic achievement scores. Pearson's moment correlation was run separately for the perceptions and academic achievements of Levels 200 and 300 elective chemistry preservice teachers and the results tabulated.

\section{Results/ Discussion}

Research question 1: What is the relationship between pre-service teachers' perceptions and their academic achievements in chemistry?

Table 1 below presents the correlation between Level 200 pre-service science teachers' perception and their academic achievement. FDC 114C denotes the course code for General Basic Chemistry that represents the students' academic achievement scores in Table 1.

Table 1.0: Correlation between Level 200 Pre-service Science Teachers' Perception and their Academic Achievement
FDC 114C
Perception

FDC 114C

Perception
1

$-0.046$
1

From Table 1.0, the results show that the correlation coefficient (r) was -0.046 . This implies that a weak negative correlation existed between Level 200 elective science students' perceptions and their academic achievement in chemistry. This means that if students' perceptions about the CoE chemistry curriculum increased, their academic achievement decreased, and vice versa. This result is consistent with the findings of Kurbanoglo and Akin (2015) in their study to develop a scale to measure organic chemistry anxiety levels of university students in Turkey, where Pearson moment correlation was used to examine the relationships between organic chemistry anxiety and the organic chemistry achievement. Correlational results $(\mathrm{r}=-0.47)$ proved that there were significant correlations between organic chemistry achievement and organic chemistry anxiety. In other words, if students' organic chemistry anxiety levels increased then their organic chemistry achievement decreased. Ferreira and Santoso (2008) confirmed that students' perceptions really matters. From their study of the effects of students' perceptions on their academic performance, their findings suggested that positive perceptions held by students at the end of the semester had a positive impact on students' performance. In the same way, negative perceptions held by the undergraduate students affected their academic performance negatively. 
Pearson moment correlation was also used to determine the relationship between Level 300 elective science students' perceptions and their academic achievement in chemistry. The results as presented in Table 2.0 show that there is weak negative correlation $(r=-0.078)$ between students' perceptions and their academic achievement. This means that, as the students' perceptions increased, their academic achievements decreased and vice versa. Findings from the Pearson moment correlation analysis for Level 300 science student also confirmed the study conducted by Kurbanoglo and Akin (2015) just as it was for the Level 200 science students.

Table 2.0: Correlation between level 300 science teacher trainees' perception and their academic achievement

FDC 114C Perception

FDC 114C

Perception
1

$-0.078$
1

The strength of the correlation coefficient for the Level 300 science students $(-0.078)$ however, was higher than that of the Level 200 science students (-0.046). Even though, they were all taught by the same tutors under the same physical environmental conditions, the Level 300 students had fully completed all the chemistry courses and had seen the outcome of their performances. The Level 200 students' however had only seen the results of General Basic Chemistry (FDC 114C). They had not yet written the end of semester examination for Basic organic and inorganic chemistry (FDC 224C), though they had completed taught component of the course as at the time of data collection and hence had not come to full terms with all factors that would culminate into their perception formation.

Research Question 2: Does the polarity of perception statements influence the correlation between students' perception and academic achievement?

Even though the study revealed that there was a correlation between science students' perceptions of the CoE chemistry curriculum and their academic achievement, the researchers sought to further probe to find out whether the nature of the perception statements (negatively or positively framed) have a relationship with pre-service science teachers' academic achievement. This was done across levels or year groups; in this case the responses to all negative statements in the questionnaire were factored into the determination of the correlation coefficient for negative perceptions. The same was applied to positive perception items.

As shown in Table 3.0, the polarity (negative or positive) of the perception statement did not produce any significant changes in the trend of correlation between pre-service elective science teachers' perceptions and their academic achievement. For instance, in respect of the correlation between pre-service teachers' perceptions about the CoE chemistry curriculum and their academic achievements (Table 3.0) based on positive perception statements, the Pearson correlation coefficient $(\mathrm{r}=-0.039)$ showed that there was a weak negative correlation. In other words, if the pre-service science teachers' perceptions dipped down, their academic achievement would increase and vice versa. 
Table 3.0: Correlation between Pre-service Science teacher's perceptions and their academic achievements based on Polarity of Statements

\section{Level/ Year Group Correlation coeffient (r) for Correlation coeffient (r) for Positive Perception statements Negative Perception statements}

$-0.039$

$-0.077$

300

$-0.018$

$-0.047$

In dealing with the correlation between pre-service teachers' perceptions and their academic achievements based on the polarity of the questionnaire items, the study revealed that the Level 200 respondents had a relatively stronger negative correlation than the Level 300 respondents. This is in contrast with the combined correlations between perceptions of each year group and their academic achievements which revealed that the Level 300 respondents had a stronger negative correlation coefficient $(r=-0.078)$ than the Level 200 respondents $(r=-0.046)$.

This confirms the popular notion that in framing Likert scale-type questionnaire items, it is always better to negate some of the items in order to produce reliable results. Cheung (2009) reported that a combination of positively and negatively worded items were often used (and still in use) by attitude researchers to reduce the effects of acquiescence and other response biases. Even though he suggested some other researchers like Miller and Cleary (1993); Pilotte and Gable (1990); Schmitt and Stults (1985) including himself have indicated that negative items, written as reversals of positive items, may load on a separate factor, forming a measurement artifact.

This study agrees with the researchers who believe in combining the negative and positive perception statements. This would actually reveal the true picture of the perceptions held by the respondents thereby reducing acquiescence bias. In this case, the combined coefficients of correlation values for Level 200 and Level $300(r=-$ 0.078 and $\mathrm{r}=-0.046$ respectively) is deemed reliable.

\section{Conclusion.}

Resolving students' negative perceptions in any academic discipline is very crucial in setting the tone for their academic progression in excellence. The issue of perceptual consequences is compounded if it has to do with Preservice teachers who themselves are going out to teach others. This study revealed that there is a negative correlation between the perceptions held by Pre-service science teachers of Tamale College of Education about the chemistry curriculum and their academic achievement $(r=-0.046$ and $r=-0.078$ for Levels 200 and 300 students respectively). This means that as their perceptions increased negatively, their academic achievement decreased. This accounted for their average achievement in the end of semester examination scores in Colleges of Education Basic Chemistry course. The study also revealed that the polarity of perception statements does not significantly affect the correlation coeffient. It is however, very imperative to combine both negative and positive statements in order to reduce acquiescence biases.

The researchers therefore recommend that trainers of science teachers should alley the fears and wrong perceptions held by students by adopting modern and better approaches to teaching the $21^{\text {st }}$ century pre-service science teachers. Doing this may call for creation of congenial and friendly learning environments where teacher trainees are able to express themselves freely, devoid of intimidation and harassment. In so doing, the trainers of preservice teachers will professionally handle teacher trainees' wrong perceptions and correct them before they offload same to their future students.

\section{Acknowledgment}

We duly acknowledge all the lecturers in the Science Faculty of the University of Education, Winneba, especially, Professor Victus Samlafo, who constructively critiqued this work. We are thankful to Mr. Isaac Agoyalig (Head of Department of Science Education), and all pre-service science students of Bagabaga College of Education who permitted us to pilot the study in their department. We cannot forget the Principal (Dr Sulemana Iddrisu), Head of 
Science Department and all the pre-service science teachers of Tamale College of Education. We appreciate the opening of their doors for us to gather data for the study from which this paper is carved from.

\section{References}

Anamuah-Mensah, J. (1995). Ordinary level chemistry topics: What students find difficult. Journal of Oguaa Educator, 11 (2), 8-18.

Cavallo, A. M. L., \& Laubach, T. A. (2001). Students' science perceptions and enrollment decisions in differing learning cycle classrooms. Journal of Science Teaching and Research, 38 (9), 1029-1062.

Cheung D. (2009). Students' attitudes toward chemistry lessons: The interaction effect between grade level and gender. Journal of Research in Science Education, Volume 39, Issue 1, pp. 75-91.

Das N., Amrita \& Singh A. (2014). Importance of Science in School Curriculum. WeSchool Knowledge Builder The National Journal, 2(1), 15-18.

Ferreira A. \& Santoso A. (2008). Do Students Perceptions Matter? A Study of the Effect of Students Perceptions

on $\quad$ Academic Performance. Accounting and Finance. 48 (2): 209-231. DOI: 10.1111/j.1467-629X.2007.00239.x

Hofstein. A., \& Mamlok-Naaman, R. (2011). High-School Students' Attitudes toward and Interest in Learning Chemistry. Education quím., 22(2), 90-102.

Kaya, E., \& Cetin, S. P. (2012). Investigation of pre-service chemistry teachers' chemistry laboratory anxiety levels. International Journal on New Trends in Education and Their Implications, 3(3), 90-98.

Kubiatko M., Mrascova, K., \& Janko, T. (2012). Gender and Grade level as factors influencing perceptions of geography. Journal of review of International Geographical Education online, 2(3), 289-302.

Kurbanoglu, N.I., \& Akın, A. (2015). Development of a scale to measure organic chemistry anxiety level of university students. Journal of Baltic Science Education, 14(3), 391-400.

Mensah, F., \& Appiah, J. Y. (2015). Science methods for basic school teachers. Accra: Mercury Press LTD.

NaCCA (2019). Science Curriculum for Primary Schools. Ministry of Education Publication, Accra.

Norman J. (2002). Two visual systems and two theories of perception: An attempt to reconcile the constructivist and ecological approaches. Journal of Behavioral and Brain Sciences, 25 (1), 73-144.

Wells, R. R. (2003). Development of an instrument to Assess Chemistry Perceptions. Doctor of Education dissertation, Unpublished.

Yüksel M., Geban Ö. (2014). A Study of the Prediction of Academic Achievement in the Chemistry Course. Journal of Science and Education. Vol. 39, No 173, 354-365.

\section{Biodata of Authors}

1. Ayoberd Arthur Samuel is a Senior Tutor and the Head of Department (HoD) for Science Education of Tamale College of Education. He holds MSc in Environmental Science and MPhil in Science Education from Kwame Nkrumah University of Science and Technology and the University of Education, Winneba - Ghana respectively. He specialises in chemistry, science pedagogy and biology teaching.

2. Yaayin Boniface is a Senior Tutor in the Science Education Department of Tamale College of Education. He is a $\mathrm{PhD}$ student with the University of Education, Winneba. Yaayin Boniface holds MSc (Water Supply and Sanitation) and MPhil (science education) from Kwame Nkrumah University of Science and Technology and the University of Education, Winneba respectively. He specialises in chemistry, integrated science and science pedagogy.

3. Collins Dauda Amadu is a Chemistry Tutor of Tamale College of Education. He holds a Master of Education (M.Ed. Science Education) from the University of Cape Coast - Ghana and is currently pursuing a Master of Philosophy in science education degree from the university of Education, Winneba.. Collins specialises in chemistry and science pedagogy. 